\title{
Use of snow cover derived from satellite passive microwave data as an indicator of climate change
}

\author{
B. E. GOODISON AND A. E. WALKER \\ Climate Research Branch, Canadian Climate Centre, 4905 Dufferin Street, Downsview, Ontario, Canada M3H 5T4
}

\begin{abstract}
To assess future global change, monitoring of the climate system through observation and analysis of seasonal and interannual fluctuations of climate variables is necessary. Cryospheric elements such as snow cover are often seen as sensitive indicators and integrators of basic climate conditions and hence an indicator of regional and global change. Snow-cover elements which may serve as signals of variability and change are discussed with respect to the effective use of conventional and remotely sensed information. Conventional data are shown to be effective for assessing questions of temporal variability, but are limited for spatial variability. Passive microwave satellite data make an important contribution by providing spatial and temporal information on snow water equivalent (SWE) and the regional distribution of snowpack extent and state. Use of NIMBUS-7 SMMR (Scanning Multichannel Microwave Radiometer) data to develop a time series of SWE is assessed as a complement to conventional data. Limitations of SMMR coverage compared to DMSP SSM/I (Special Sensor Microwave/Imager) coverage for production of SWE maps for climate change analysis are discussed. Although there are limitations during early season snow cover, information derived from passive microwave data is shown to be able to map and compute the areal coverage of SWE allowing interannual comparison of the amount of water available, the date of peak accumulation and the associated spatial distribution. However, the satellite data record is still too short to establish any definitive trend in snow-cover variability.
\end{abstract}

\section{INTRODUCTION}

The recent work of the Intergovernmental Panel on Climate Change (Houghton and others, 1990) provided the first major assessment of the evidence of, and the potential for, climate change. It is acknowledged that there are many uncertainties in the prediction of future climate changes, particularly with respect to timing, magnitude, and regional patterns of change. Monitoring of the climate system through systematic observation and analysis of climate-related variables on a global, national and regional basis is one contribution to improving our predictive capability. Identification of a significant change in a climate variable is an integral part of this monitoring.

The highest priority science question identified by the EOS Panel on Physical Climate and Hydrology (Barron, 1991) was to determine how the global and regional storages and fluxes of water, including snow cover in northern latitudes, will interact with a change in climate. The IPCC (Houghton and others, 1990) noted that snow, ice and glacial extent are key variables in the global climate system and that accurate information on cryospheric changes is essential for full understanding of this system. Cryospheric components are often very sensitive indicators and integrators of basic climate elements, such as precipitation, temperature and solar radiation. Variations in snow cover, therefore, may potentially be an effective indicator of regional and global change. But has the science community defined key elements which should be routinely monitored on a regional or global basis in order to assess natural variability or to detect climate change? This paper proposes some of the elements of snow cover which may be a reflection of climate variability and change, and discuss the potential contribution of conventional and remotely sensed data, with particular emphasis on passive microwave data.

\section{SNOW GOVER AS AN INDICATOR OF GLIMATE VARIABILITY AND CHANGE}

The development of a consistent, compatible data series for spatial and temporal analyses of snow cover variability is critical. Extraction of a data set complete enough to address the problem at hand can be time consuming and costly; this is even more critical when using satellite data since the volume of data to be processed and analysed is much greater than conventional data.

Inherently we feel that cryospheric changes should reflect changes in climate, but in the case of snow cover what aspect(s) should we monitor? Should it be the:

- change in snow water equivalent at peak accumulation for selected locations?

- change in date of the peak accumulation?

- northward retreat of the snowline on a given date? 
- change in the spatial distribution of snow cover over a region?

- change in number of days of continuous snow cover?

- change in date of the beginning or end of continuous snow cover?

- change in the date of the onset of spring melt?

- change in the frequency of the number of melt events during the winter season?

- mapping and identification of temporal outliers from the main accumulation period?

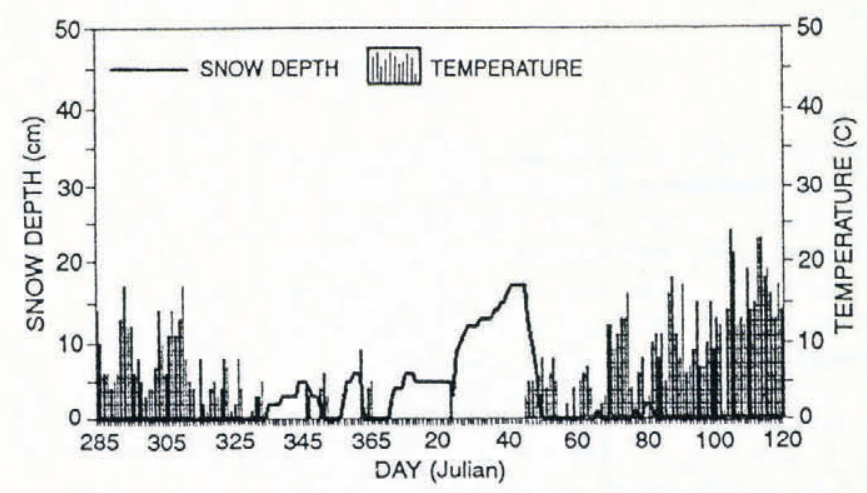

Fig. 1. Daily snow depth (cm) and maximum air temperature (above $0^{\circ} \mathrm{C}$ ) for Regina, Saskatchewan, October 1980 to April 1981.

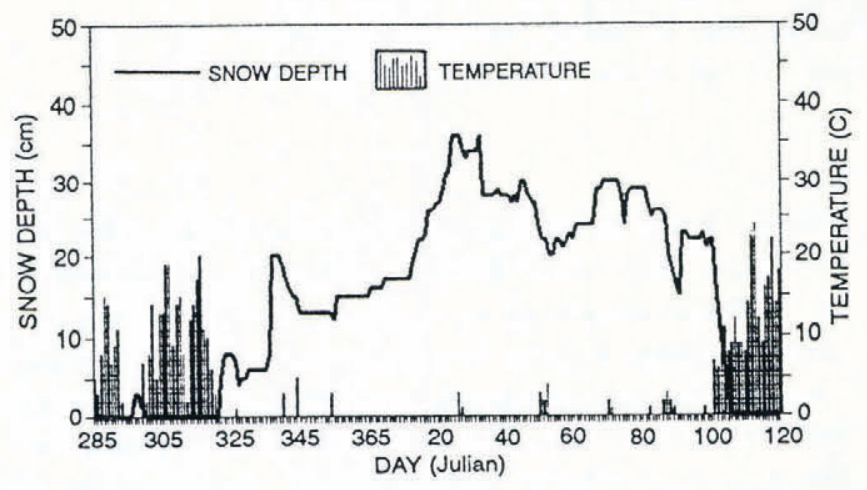

Fig. 2. Daily snow depth (cm) and maximum air temperature (above $0^{\circ} \mathrm{C}$ ) for Regina, Saskatchewan, October 1981 to April 1982.

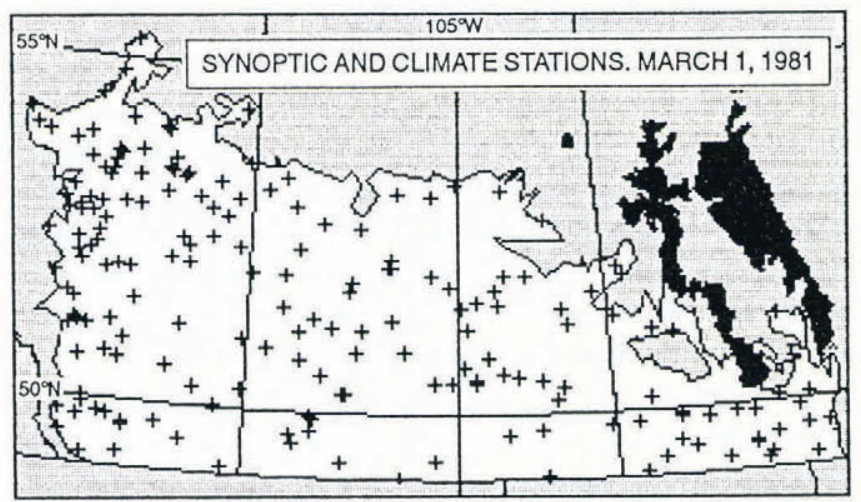

Fig. 3. Distribution of Atmospheric Environment Service (AES) synoptic and climate stations with recorded snow depth measurements on 1 March 1981.
These are only some of the potential "signals" which might be used. However, each requires data to be analyzed differently. The frequency of the collection, archiving, and processing of conventional or satellite data into product information may range from daily, weekly or monthly or be limited to a set date. The question of integrating ground data collected at specific locations and on certain dates with remote sensing information must be addressed. These are fundamental issues which must be assessed by researchers as they develop a strategy for using snow cover as an indicator of climate variability and change.

Ideally, the routine analysis of the regional and global distribution, amount and spatial variability of snow cover should involve both conventional and remotely sensed information. The network of surface based observations of snow cover is quite dense in the continental regions of the mid-latitudes, although a comprehensive archive of these observations does not yet exist. However, data from these stations can be used effectively, and still form the basis of much of our analyses of snow-cover variability and change on a regional basis. Figures 1 and 2 compare snow cover for Regina, Saskatchewan for the 1980-81 and 1981-82 winter seasons as depicted by the daily snow depth recorded at the synoptic station. Occurrences of daily maximum temperatures above $0^{\circ} \mathrm{C}$ are also plotted and provide an indication of possible melt events. The two winter periods are quite different, with 1981-82 exhibiting a more continuous snow cover with few winter melt events. A time series of these archived data can contribute directly to addressing several of the elements noted above. One can compare differences in the amount and date of maximum snow accumulation, the number of days of continuous snow cover, differences in the onset and ending of continuous snow cover, and so on. However, there is no information about spatial variability of the snow cover. Other synoptic or climate station data would be required in order to derive spatial snowcover information for a region of interest; the representativeness of the information would depend upon the density of the station network. Figure 3 depicts the distribution of synoptic and climate stations over the Canadian prairie region where snow depth measurements were recorded on 1 March 1981. Although there are 190 stations within the study area, their spatial distribution is not consistent over the region; reliable information about the spatial variability of snow depth would be limited in the areas where the stations were widely spaced.

To get a better global scale perspective of snow extent one would more likely use the NOAA/NESDIS weekly northern hemisphere snow-cover maps (snow/no-snow) derived from visible satellite imagery (e.g. NOAA, GOES, METEOSAT) (Wiesnet and others, 1987). Recent re-analysis by Robinson and others (1991) of this product to assess the change in global snow cover showed a decrease in snow cover of about $8 \%$ from the mid-1970s to the late 1980s, with snow extent being especially low in spring since 1987. However, these products can only address the issue of snow-covered area, and its variability, not the water equivalent or depth of a snow cover. 


\section{GONTRIBUTION OF PASSIVE MICROWAVE INFORMATION}

One of the limitations of the NOAA weekly chart is that it is a weekly composite map derived from visible satellite data; cloud cover will preclude accurate assessment of the snow extent on any given day and sometimes it is necessary to use the extent derived during the previous week. This is a natural limitation of all optical data for operational snow-cover mapping. A major advance in the remote sensing of snow cover has been the development of algorithms to determine snow depth, water equivalent, areal extent and snow state (wet/dry) using microwave satellite sensors having all-weather capabilities (Chang and others, 1990; Goodison, 1989; Goodison and others, 1986; Goodison and others, 1990; Hallikainen and Jolma, 1992; Kunzi and others, 1982).

The authors have developed algorithms to derive snow water equivalent (SWE), areal extent and snowpack state (wet/dry) for open regions from satellite passive microwave data. These algorithms were developed from intensive airborne studies over the Canadian prairies and tested using NIMBUS-7 SMMR and DMSP SSM/I data for this mid-continent region (Goodison, 1989; Goodison and others, 1986, 1990). They are now used to produce operational snow water equivalent maps for the prairie region of Canada and the U.S.A. from DMSP SSM/I data on a real-time basis (Thirkettle and others, 1991). Although this research was initiated to support hydrology, the derived snow-cover information is now being assessed for its potential in the study of climate and global change. The use of snow cover as an indicator of climate change and the effective use of passive microwave data for such analyses became very real issues in the authors' recent effort to produce a snow-cover time series for the Canadian prairies for the SMMR period (197886 ) as a contribution to the International Space Year (ISY).

Although a reliable, accessible archive of passive microwave data is readily available since the launch of NIMBUS-7 SMMR in 1978, there are some practical limitations to the production of snow cover time series, even for relatively small regions. The Canadian open prairie region spans a longitude of only $18^{\circ}$ and covers an area of only $512560 \mathrm{~km}^{2}$. However, the SMMR swath was only $800 \mathrm{~km}$ wide and due to satellite power constraints the sensor was operated every second day. Data from two or three successive operational periods were required to provide complete coverage of the study area, resulting in a composite map of snow cover for a three-to-five day period (Fig. 4). One is then forced to analyze a weekly composite of snow cover rather than a daily product. Changing weather patterns over the fiveday period could produce changes in the SWE and distribution of snow cover and changes in the occurrence and distribution of melt areas or wet snow (resulting in an underestimation of SWE and snow covered area from the microwave data) which would produce a non-representative picture of snow cover across the region for the period.

The situation is much improved for the operational DMSP SSM/I data, which have been available since 1987 , as the $1400 \mathrm{~km}$ swath provides daily coverage of this

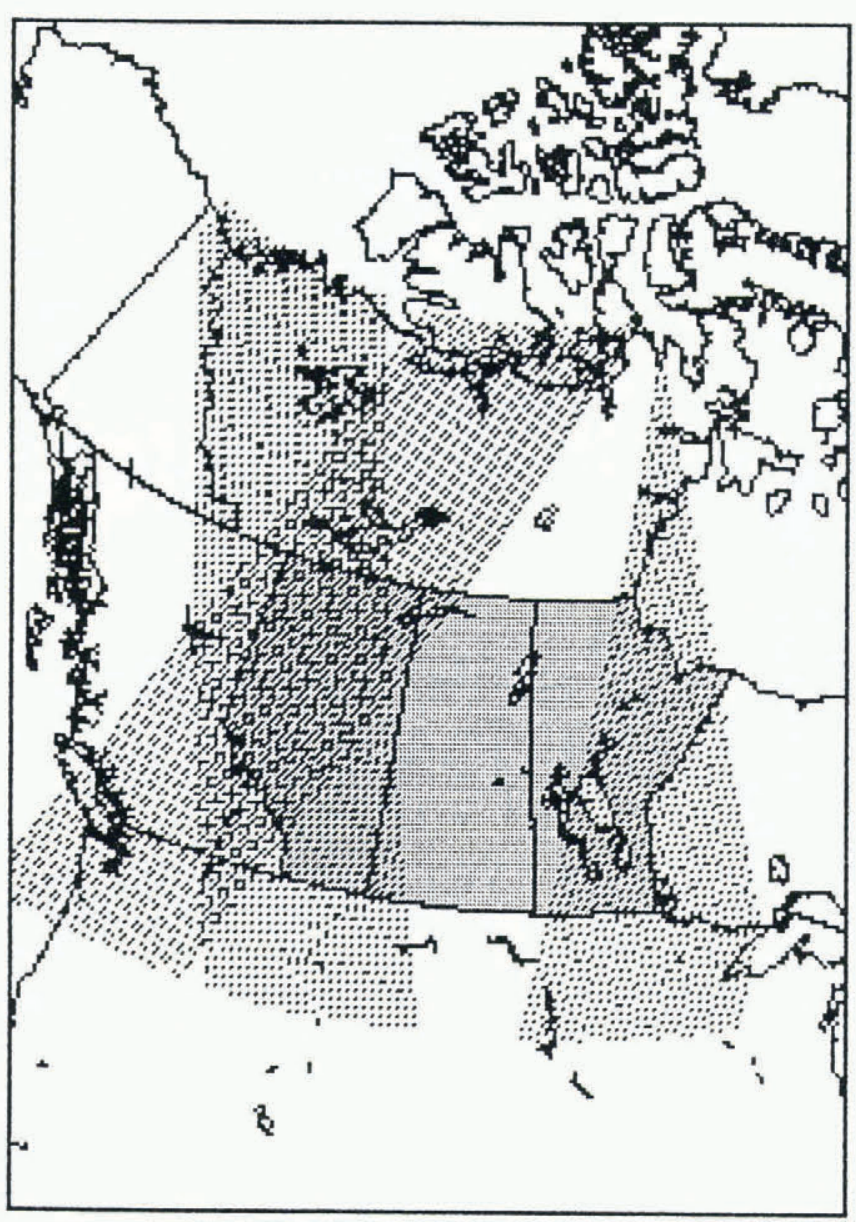

Fig. 4. Nimbus-7 SMMR swath coverage for a single day (DAY 1) over Western Canada. For complete coverage of the southern Canadian prairies, data were required from orbits over a five-day interval (DAYS 1, 3 and 5).

particular study area, eliminating the problem of compositing and interpretation of potential artificial variations in snow cover (Fig. 5). Daily coverage of the study region is preferred, allowing easy comparison with conventional ground based data from synoptic and climate staions and snow courses. Use of data from SMMR and SSM/I to produce a consistent, compatible time series of snow cover from year to year will be difficult and must be done with care and caution; products from the two satellite sensors cannot be directly compared unless the same compositing procedure is used for both data sets. Hence the authors have restricted their current analysis for the ISY study to the SMMR time period.

As noted above, NOAA AVHRR data are used to produce maps of global snow cover extent. These data, having a $1 \mathrm{~km}$ spatial resolution, are also useful for regional analyses. However, only information on snow extent can be derived and the problem of cloud cover can limit the effectiveness in assessing the actual dates of the beginning or end of snow cover. This has been particularly true for the fall period. It was expected that passive microwave data could overcome some of these limitations. As noted above, algorithms have been developed and are being validated to derive snow water equivalent from passive microwave data. The current 


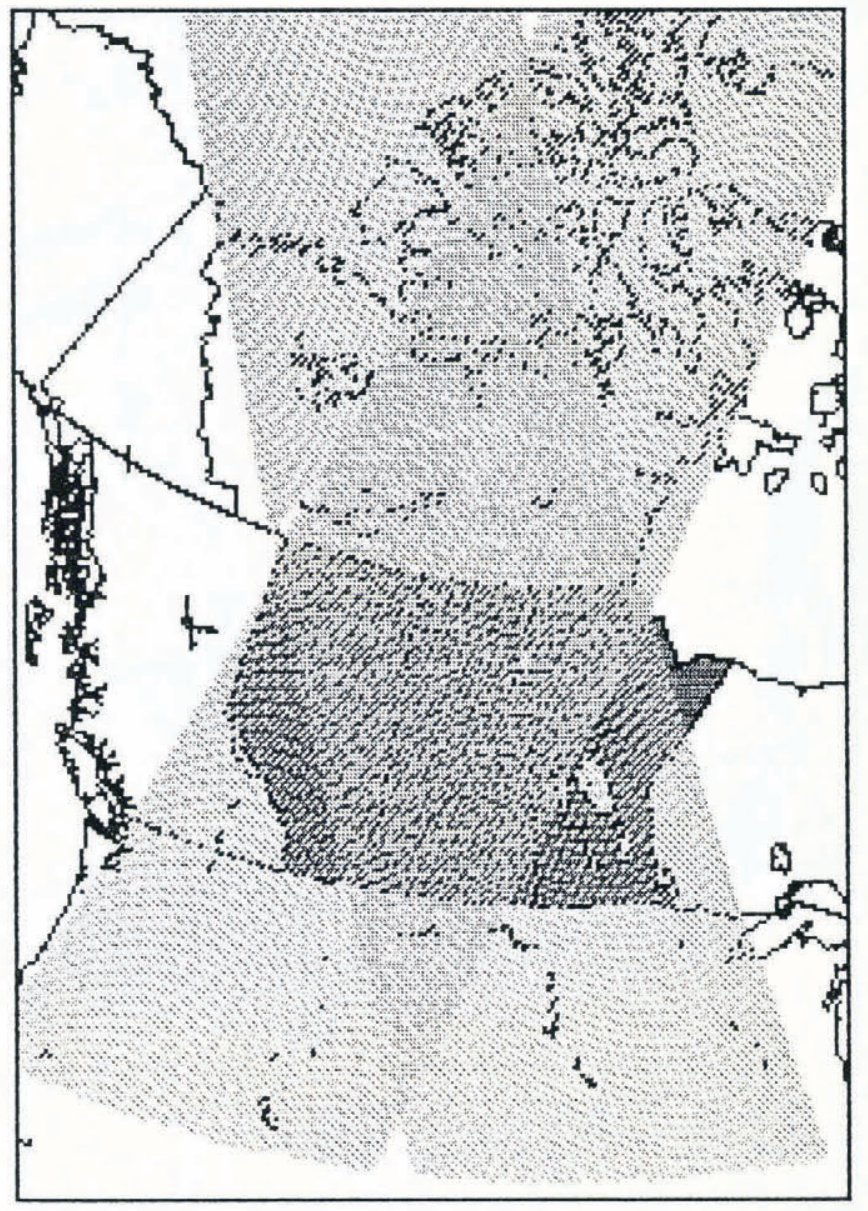

Fig. 5. DMSP SSM/I swath coverage over Western Canada. Complete coverage of the Canadian prairie region can be obtained on a daily basis using one ascending and one descending pass.

operational SWE algorithm uses the vertically polarized brightness temperature gradient between 37 and $19 \mathrm{GHz}$ for SMM/I and 37 and $18 \mathrm{GHz}$ for SMMR. Success has been achieved for open areas when there is dry snow; SWE retrievals are generally within $10-20 \mathrm{~mm}$ of averaged ground-based survey measurements (Goodison, 1989). Figures 6 and 7 show the regional snow water equivalent as derived from SMMR data for the first week of March in 1981 and 1982. The large difference in areal coverage and distribution between the two years is readily evident. It is this type of information, put into a weekly time series for every snow cover season, that can be assessed for variability and change analyses. It complements the information available for individual stations (see Figs 1 and 2), and provides the spatial distribution of SWE which is not available from conventional or other remote sensing observations. For example, Figure 1 shows there is no snow cover at Regina; Figure 6 illustrates how large an area is actually devoid of snow. Figure 2 provides a detailed daily time profile of snow depth at Regina, suggesting extensive cover during the 1981-82 winter; Figure 7 shows that in fact the area of peak accumulation was centered near Regina and other areas within the region had considerably less snow.

An acknowledged limitation of passive microwave data is that SWE cannot be derived when there is liquid

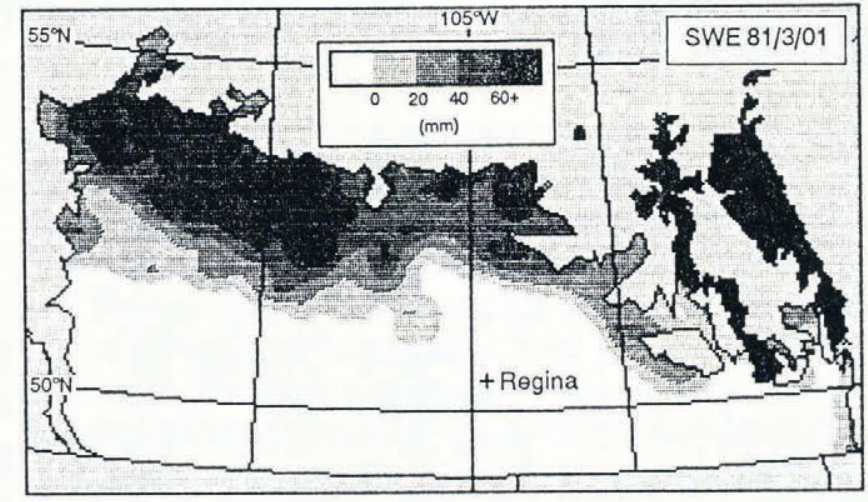

Fig. 6. Distribution of snow water equivalent over the Canadian prairies for 1 March 1981 derived from Nimbus-7 SMMR data.

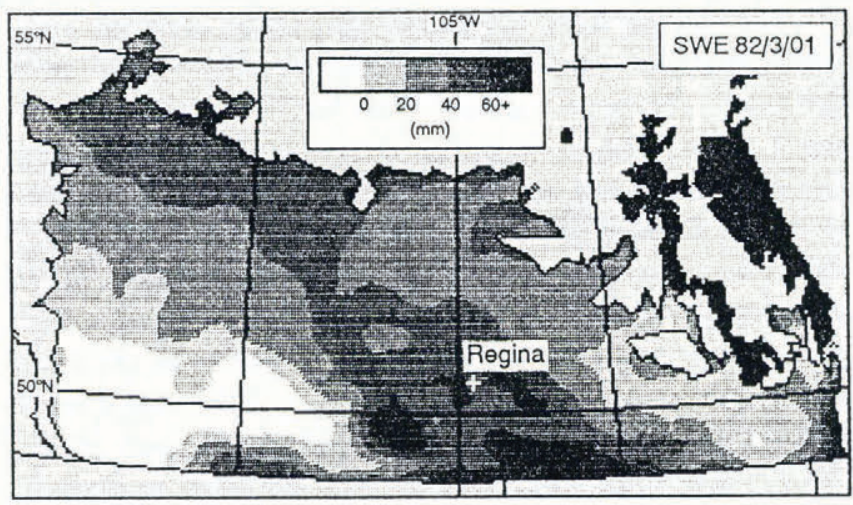

Fig. 7. Distribution of snow water equivalent over the Canadian prairies for 1 March 1982 derived from Nimbus-7 SMMR data. water within the snowpack. Walker and Goodison (1993) present a method for mapping areas of wet snow, thus allowing a more accurate determination of areal extent. This technique has been validated for SSM/I data but has not been verified for SMMR data and has not been applied to this time series analysis of SMMR derived snow cover. Special attention has been given to the ability of passive microwave to map snow cover during the beginning of the snow-cover season when the pack is shallow and may be wet and the ground may be warm and unfrozen. Using the current algorithm, without the wet snow indicator, there has been some difficulty in accurately mapping SWE. Figure 8 depicts the SWE derived for 1 December 1983, when there was a complete, but relatively shallow, snow cover over the entire prairie area. SWE measured at Atmospheric Environment Service snow courses ranged from 8 to $33 \mathrm{~mm}$, with a minimum snow depth of $7-10 \mathrm{~cm}$; temperatures were below freezing at the time of the satellite overpass. However, the shallow light density snow was not readily seen. Warm ground temperatures which can produce a melt layer at the bottom of the snowpack are suspected to be one of the contributing causes to this problem. Assessment of the limitations during these conditions is on-going; at the moment this problem does limit the effectiveness in accurately defining the onset of continuous 


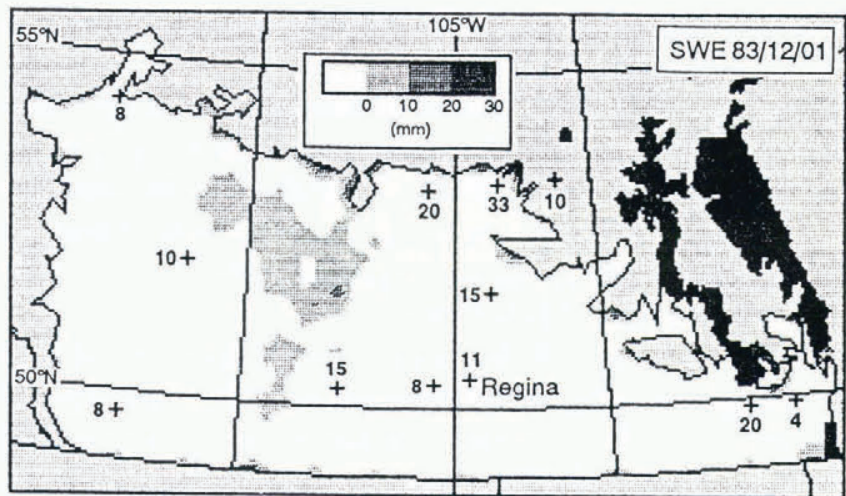

Fig. 8. Distribution of snow water equivalent over the Canadian prairies for 1 December 1983 derived from Nimbus-7 SMMR data. Values are SWE in $\mathrm{mm}$ measured at snow courses at synoptic weather stations.

snow cover over an area. Research has been initiated in Europe on the use of 19,37 and $85 \mathrm{GHz}$ data from SSM/I to map shallow snow cover (Nagler and Rott, 1992).

Snow-cover maps derived from passive microwave data do offer the great advantage of assessing changes in areal snow-cover water equivalent during the winter and from year to year, allowing for the current limitations noted above. Figures 9 and 10 compare the snow covered area for the first weeks of February and March for 1979 to 1986. Early February shows the tendency to have a higher percentage of snow covered area over the entire prairie area than during early March. The March survey, however, may give a better indication of the potential for soil moisture recharge and runoff than the earlier survey alone. For this period, no clear trend emerges with respect to snow cover over the prairies; the SMMR record is just too short to draw conclusions about climate variability and change. When properly combined with SSM/I and conventional records, the record can be extended to allow for a more accurate analysis of temporal variability.

Another substantial contribution of the passive microwave derived snow cover product is its ability to map and compute the areal coverage of SWE, thus allowing comparison of the amount of water available from year to year. Figure 11 compares the area covered by different amounts of snow water equivalent, in this example using $20 \mathrm{~mm}$ increments. For example, 1986 was characterized by both low areal extent and low water equivalent; 1981 on the other hand had low areal extent, but had a considerably higher water equivalent where there was snow. Again no discernible trend is evident over the SMMR period for areal coverage of a particular amount of water equivalent. The satellite data are the only viable data source for assembling these statistics on snow cover and amount on a weekly basis. The conventional record cannot provide the spatial variability for such an analysis and only snow courses can provide a measurement of SWE; there are too few of these sites to construct an accurate areal picture on a weekly time scale throughout the season.

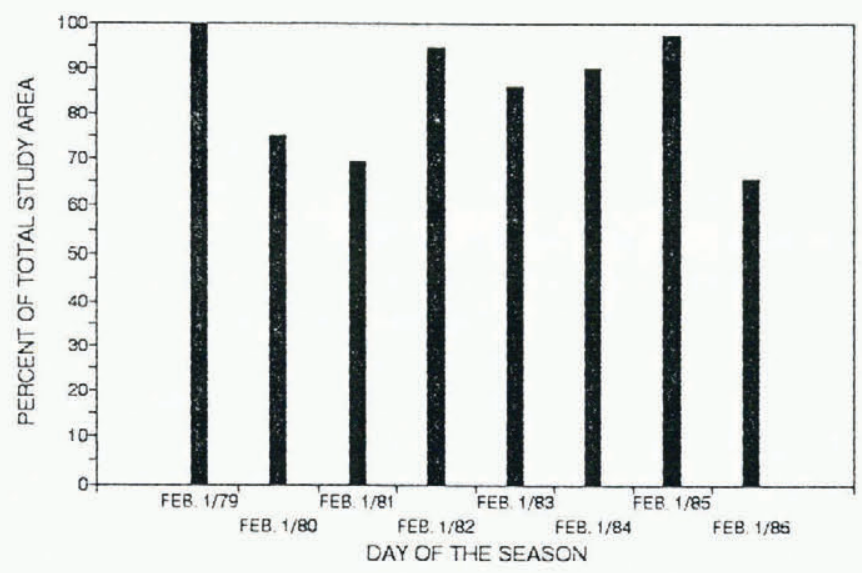

Fig. 9. Snow cover as a percentage of total area of the Canadian prairies region for the first week of February, 1979 to 1986.

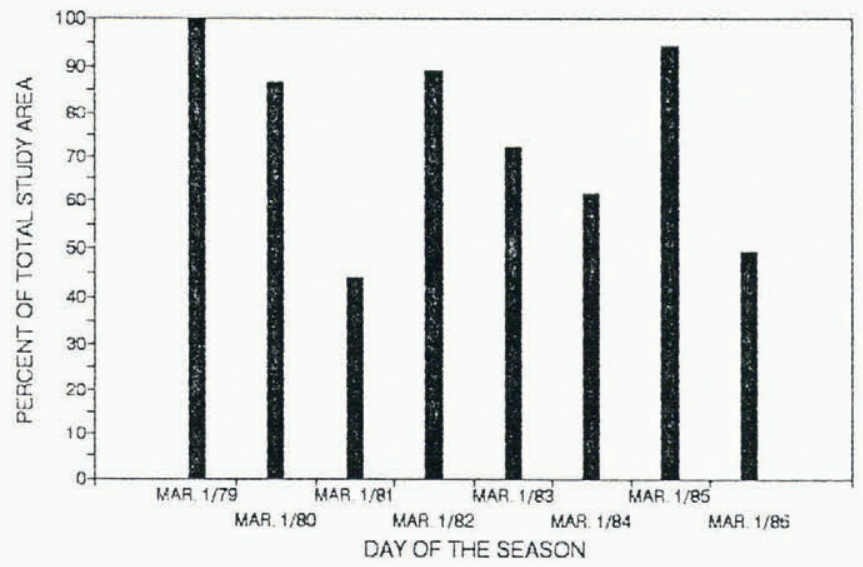

Fig. 10. Snow cover as a percentage of total area of the Canadian prairies region for the first week of March, 1979 to 1986 .

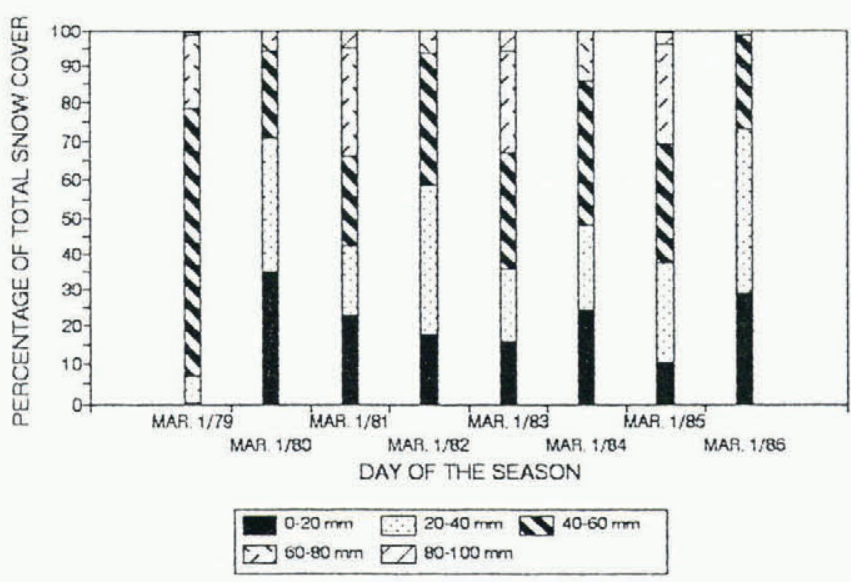

Fig. 11. Snow cover as a percent of total snow covered area for $20 \mathrm{~mm}$ intervals of snow water equivalent, for the first week of March, 1979 to 1986. 


\section{CONCLUSIONS}

Passive microwave data provide another very useful source which will contribute to the effective analysis of variations in snow cover and climate. These data should be used in conjunction with conventional ground observations and other remotely sensed information, such as derived from NOAA AVHRR, in order to derive the most representative time series of snow cover information. If key snow-cover elements are to be monitored for evidence of regional or global climate change, the passive microwave data offer the following advantages:

(i) determination of areal extent and snow water equivalent over a region;

(ii) determination of the date of peak accumulation and the interannual variability over a region;

(iii) assessment of the onset of spring melt, the areal extent of melt regions and the frequency of occurrence.

However, there are still limitations to the exclusive use of snow-cover information from passive microwave data for change analysis. It is not possible to derive SWE when the snowpack is wet, hence limiting its use to map SWE through to the disappearance of the pack. There are still limitations in snow-cover retrievals during the early fall period when the ground is warm and the snow pack is shallow. These two factors limit determination of the beginning and end of the period of continuous snow cover. It is clear that regional snow-cover algorithms are required, and at the moment, retrievals in forested and mountain regions are still under development. Finally, like with all other satellite retrievals of climate elements, there is the question of the consistency and compatibility of the method of measurement. For passive microwave data, snow cover products from SMMR using a three-tofive day integration period will not be totally compatible with a daily product from SSM/I. Daily snow cover information derived from SSM/I data are going to be much more useful in developing a time series which can be combined with conventional data for the assessment of snow cover variability and change. At the moment, however, the satellite record is too short for climate change analysis.

\section{ACKNOWLEDGEMENTS}

Support for the compilation of the ISY snow atlas for the Canadian prairies has been received from the Canadian Space Agency and from the Global Warming Science Green Plan initiative led by Environment Canada. Special thanks are extended to David Olson for data display and analysis.

\section{REFERENGES}

Barron, E. 1991. Panel report on physical climate and hydrology. Earth Observer, 3(7), 18-22.

Chang, A. T. C., J. L.Foster and D. K. Hall. 1990. Effect of vegetation cover on microwave snow water equivalent estimates. In Proceedings of the International Symposium on Remote Sensing and Water Resources, Enschede,
The Netherlands, August 1990. International Association of Hydrologists, 137-146.

Goodison, B. E. 1989. Determination of areal snow water equivalent on the Canadian prairies using passive microwave satellite data. IGARSS'89. 12th Canadian Symposium on Remote Sensing. Quantitative remote sensing: an economic tool for the nineties, Vancouver, Canada, July 10-14, 1989. Volume 3, 1243-1246.

Goodison, B. E., I. Rubinstein, F. W. Thirkettle and E. J. Langham. 1986. Determination of snow water equivalent on the Canadian prairies using microwave radiometry. International Association of Hydrological Sciences Publication 155 (Symposium at Budapest 1986 - Modelling Snowmelt-Induced Processes), 163-173.

Goodison, B. E., A. E. Walker and F. W. Thirkettle. 1990. Determination of snow cover on the Canadian prairies using passive microwave data. In Proceedings of the International Symposium on Remote Sensing and Water Resources, Enschede, The Netherlands, August 1990. International Association of Hydrologists, 127-136.

Hallikainen, M. T. and P. A. Jolma. 1992. Comparison of algorithms for retrieval of snow water equivalent from Nimbus-7 SMMR data in Finland. IEEE Trans. Geosci. Remote Sensing, 30(1), 124-131.

Houghton, J. T., G.J. Jenkins and J.J. Ephraums, eds. 1990. Climate change: the IPCC scientific assessment. Cambridge, Cambridge University Press.

Kunzi, K.F., S. Patil and H. Rott. 1982. Snow-cover parameters retrieved from Nimbus-7 Scanning Multichannel Microwave Radiometer (SMMR) data. IEEE Trans. Geosci. Remote Sensing, GE20(4), 452-467.

Nagler, T. and H. Rott. 1992. Development and intercomparisons of snow mapping algorithms based on SSM/I data. IGARSS'92. International Geoscience and Remote Sensing Symposium. International Space Year: space remote sensing, Houston, Texas, May 26-29, 1992. New York, Institute of Electrical and Electronics Engineers, 812-814.

Robinson, D.A., F. T. Keimig and K.F. Dewey. 1991. Recent variations in Northern Hemisphere snow cover. In Proceedings of the 15th NOAA Annual Climate Diagnostics Workshop, Asheville, NC, October 29-November 2, 1990. Asheville, NC, National Oceanic and Atmospheric Administration, 219-224.

Thirkettle, F., A. Walker, B. Goodison and D. Graham. 1991. Canadian prairie snow cover maps from near real-time passive microwave data: from satellite data to user information. In Franklin, S., M. D. Thompson and F.J. Ahern, eds. Proceedings of the 14th Canadian Symposium on Remote Sensing, Calgary, May 1991. Ottawa, Canadian Remote Sensing Society, 172-177.

Walker, A. E. and B.E. Goodison. 1993. Discrimination of a wet snow cover using passive microwave satellite data. Ann. Glaciol., 17 (see paper in this volume).

Wiesnet, D. R., C. F. Ropelewski, G.J. Kukla and D. A. Robinson. 1987. A dicussion of the accuracy of NOAA satellite-derived global seasonal snow cover measurements. International Association of Hydrological Sciences Publication 166 (Symposium at Vancouver 1987 Large-Scale Effects of Seasonal Snow Cover), 291-304.

The accuracy of references in the text and in this list is the responsibility of the authors, to whom queries should be addressed. 